\title{
Indirect effects of the covid-19 pandemic on childhood infection in England: population based observational study
}

Check for updates

\section{FAST TRACK}

\section{${ }^{1}$ Oxford Vaccine Group,}

Department of Paediatrics,

University of Oxford, Oxford, UK

${ }^{2}$ NIHR Oxford Biomedical

Research Centre, Oxford, UK

${ }^{3}$ Unit of Health-Care Epidemiology,

Big Data Institute, Nuffield

Department of Population Health

University of Oxford, Oxford, UK

Correspondence to: S Kadambari Seilesh.kadambari@paediatrics.

ox.ac.uk

(ORCID 0000-0003-3658-7635)

Additional material is published

online only. To view please visit

the journal online.

Cite this as: $B M J$ 2022;376:e067519

http://dx.doi.org/10.1136/

bmj-2021-067519

Accepted: 29 November 2021

\author{
Seilesh Kadambari, ${ }^{1,2}$ Raphael Goldacre, ${ }^{3}$ Eva Morris, ${ }^{3}$ Michael J Goldacre, ${ }^{3}$ Andrew J Pollard ${ }^{1,2}$
}

\section{ABSTRACT}

OBJECTIVE

To assess the impact of the covid-19 pandemic on hospital admission rates and mortality outcomes for childhood respiratory infections, severe invasive infections, and vaccine preventable disease in England.

\section{DESIGN}

Population based observational study of 19 common childhood respiratory, severe invasive, and vaccine preventable infections, comparing hospital admission rates and mortality outcomes before and after the onset of the pandemic in England.

SETTING

Hospital admission data from every NHS hospital in England from 1 March 2017 to 30 June 2021 with record linkage to national mortality data.

\section{POPULATION}

Children aged 0-14 years admitted to an NHS hospital with a selected childhood infection from 1 March 2017 to 30 June 2021.

\section{MAIN OUTCOME MEASURES}

For each infection, numbers of hospital admissions every month from 1 March 2017 to 30 June 2021, percentage changes in the number of hospital admissions before and after 1 March 2020, and adjusted odds ratios to compare 60 day case fatality outcomes before and after 1 March 2020.

RESULTS

After 1 March 2020, substantial and sustained reductions in hospital admissions were found for all but one of the 19 infective conditions studied. Among

\section{WHAT IS ALREADY KNOWN ON THIS TOPIC}

Childhood immunisation programmes in high and low income countries have been disrupted since the onset of the covid-19 pandemic owing to barriers in accessing or administering vaccines

Data from laboratory surveillance studies indicate worldwide reductions in some childhood infections since the onset of the pandemic

Reports have shown delayed presentations to paediatric emergency departments in the UK and in other countries, but the impact of such delays on patient outcomes is unclear

\section{WHAT THIS STUDY ADDS}

In the 12 months after the onset of the covid-19 pandemic, large and sustained reductions were found in rates of hospital admissions for a wide range of severe, respiratory, and vaccine preventable childhood infections in England

Absolute numbers of deaths within 60 days of hospital admission for sepsis, meningitis, bronchiolitis, pneumonia, viral wheeze, and upper respiratory tract infections also decreased

More recent data indicate that croup and upper respiratory tract infections increased to higher levels than usual after May 2021 the respiratory infections, the greatest percentage reductions were for influenza (mean annual number admitted between 1 March 2017 and 29 February 2020 was 5379 and number of children admitted from 1 March 2020 to 28 February 2021 was 304, 94\% reduction, $95 \%$ confidence interval $89 \%$ to $97 \%$ ), and bronchiolitis (from 51655 to $9423,82 \%$ reduction, $95 \%$ confidence interval $79 \%$ to $84 \%$ ). Among the severe invasive infections, the greatest reduction was for meningitis ( $50 \%$ reduction, $47 \%$ to $52 \%$ ). For the vaccine preventable infections, reductions ranged from $53 \%$ (32\% to $68 \%$ ) for mumps to $90 \%$ ( $80 \%$ to $95 \%$ ) for measles. Reductions were seen across all demographic subgroups and in children with underlying comorbidities. Corresponding decreases were also found for the absolute numbers of 60 day case fatalities, although the proportion of children admitted for pneumonia who died within 60 days increased (age-sex adjusted odds ratio 1.71, 95\% confidence interval 1.43 to 2.05 ). More recent data indicate that some respiratory infections increased to higher levels than usual after May 2021.

\section{CONCLUSIONS}

During the covid-19 pandemic, a range of behavioural changes (adoption of non-pharmacological interventions) and societal strategies (school closures, lockdowns, and restricted travel) were used to reduce transmission of SARS-CoV-2, which also reduced admissions for common and severe childhood infections. Continued monitoring of these infections is required as social restrictions evolve.

\section{Introduction}

Children younger than 16 years have accounted for less than $2 \%$ of all people with covid-19. ${ }^{1-3}$ One of the earliest and largest epidemiological studies in children with symptomatic covid-19 showed that only 13 of $2143(0.6 \%)$ children had developed critical illness. ${ }^{4}$ In Europe and North America, less than 1\% of children admitted to hospital with covid-19 have died. ${ }^{56}$

The indirect effects of covid-19 on children's health appear to be substantial. Delayed presentations to the paediatric emergency department because of disruption in healthcare services, caregiver anxiety in being exposed to SARS-CoV-2 in a healthcare setting, and inconsistent public health messaging have been reported. ${ }^{7-9}$ Additionally, routine childhood immunisation programmes have been interrupted during the pandemic. In May 2020, the World Health Organization reported that services had been suspended or postponed in 68 lower income countries, affecting more than 80 million children younger than 1 year. This disruption is partly because of a lack of transport of vaccines between countries and a shortage of healthcare staff. ${ }^{10}$ In spring 2020, 22\% of infants in the WHO European 
region had their vaccination courses interrupted. ${ }^{11}$ The first UK national lockdown began in March 2020, after which in London there was a reported 20\% reduction in measles, mumps, and rubella vaccination counts, ${ }^{12}$ although national coverage of most routine childhood immunisations subsequently increased during 2020. ${ }^{13}$ Monitoring the rates of vaccine preventable disease, with disruptions to vaccinations and as herd immunity potentially wanes, is critical to understanding how to adapt immunisation programmes during the pandemic and achieve high rates of coverage. In addition to delayed presentations, attendances to paediatric emergency departments in countries worst affected by covid-19 have reduced considerably since the onset of the pandemic. $^{8} 1415$ During 2020, laboratory surveillance data and observational studies worldwide have shown major decreases in some childhood infections, which might have contributed to this reduction. ${ }^{15-19}$

Robust population based data are required to quantify and evaluate paediatric infection related admissions to hospital during the pandemic and their outcomes to provide evidence based public health messaging and policy implementation. The primary objective of this study was to assess the indirect effects of the covid-19 pandemic on hospital admissions for childhood infections in England. Specifically, this study reports on numbers of hospital admissions in England for 19 different respiratory infections, severe invasive infections, and vaccine preventable diseases in the 12 months from 1 March 2020 compared with the previous three years. Admissions with a diagnosis of covid-19 are also reported for reference. Our

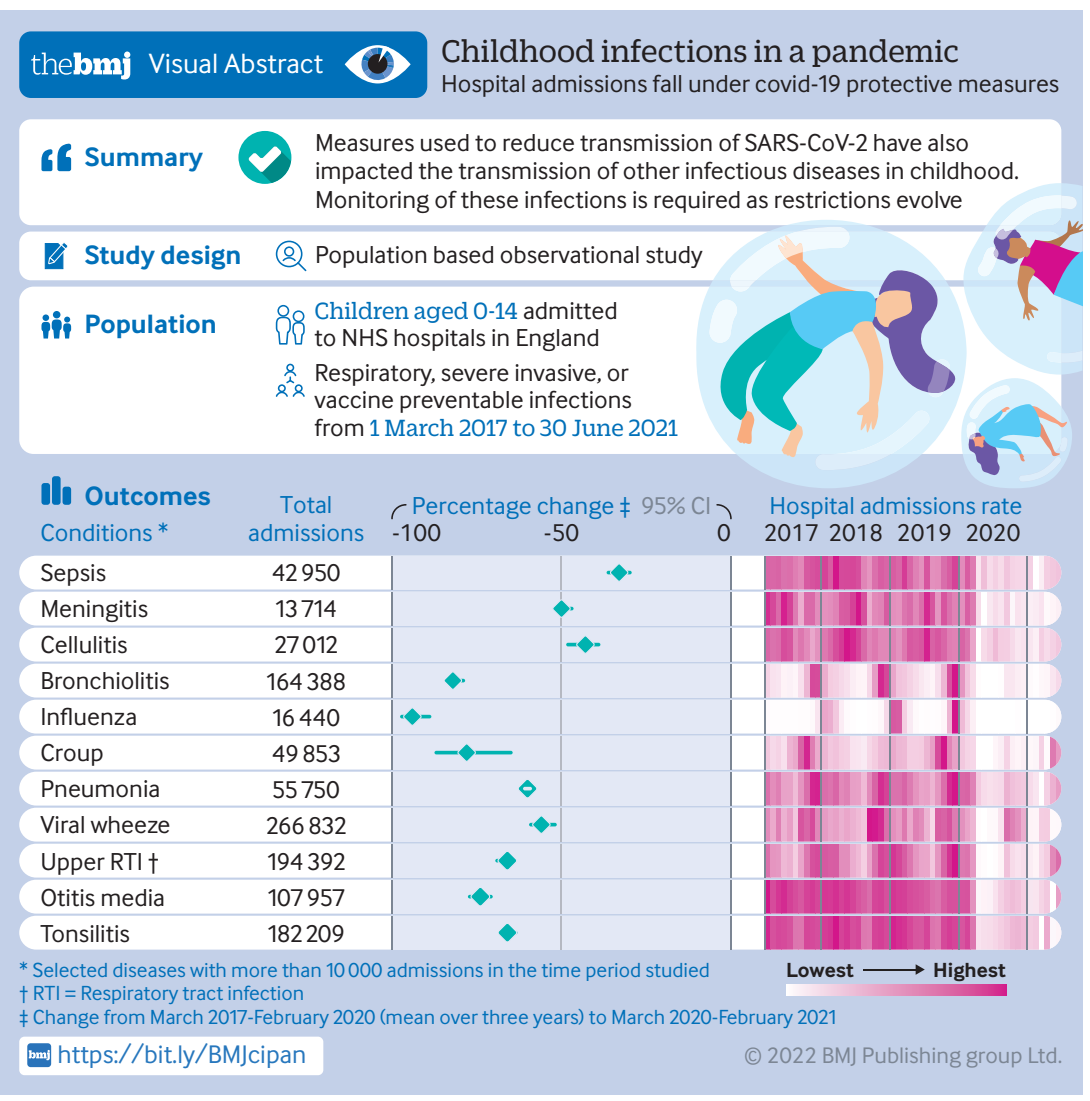

hypothesis was that the burden of childhood infections would be lower during the covid-19 pandemic because of a range of behavioural or societal measures that were implemented, but that an increase in vaccine preventable infections might occur. Future analyses will continue to track patterns of care until the challenges associated with the pandemic diminish.

\section{Methods}

\section{Data sources}

All episodes of care for children younger than 15 years admitted to NHS hospitals in England from 1 March 2017 to 30 June 2021 with the specified infections defined using ICD-10 (international classification of diseases, 10th revision; table 1) were extracted from a national dataset of Hospital Episode Statistics Admitted Patient Care records (HES) collected and supplied by NHS Digital. These records were linked to national mortality records collected by the Office for National Statistics (see linkage methods at https:// digital.nhs.uk/data-and-information/data-tools-andservices/data-services/linked-hes-ons-mortality-data). Comprehensive timelines outlining the UK government response, through laws and lockdowns, can be found in a report published by the House of Commons library. ${ }^{20}$

\section{Study design}

This is a population based observational study of children aged 0-14 in England. Supplementary table 1 shows the size of the population (population counts for 2021 were not available). Monthly counts of admissions in children aged 0-14 with each infection were determined from 1 March 2017 to 30 June 2021. These counts were aggregated into four 12 month periods from March 2017 to February 2021; the numbers of admissions in the 12 months from 1 March 2020 to 28 February 2021 were compared with the mean annual numbers from the preceding three years. From March 2021 onwards, comparisons were made on a monthly basis; that is, the numbers of admissions in each month in 2021 were compared with the mean number of admissions in the equivalent month in the three years from 2017 to 2019. Subgroup analyses were conducted by sex, age, geographical region, index of multiple deprivation, ${ }^{21}$ ethnic group, and by the comorbidities listed in table 1 (which were obtained by searching the patients' hospital admission records from birth). For conditions where admission numbers were sufficiently high, the consistency of findings across individual NHS hospital trusts was investigated. Admissions that were followed by a recorded date of death within 60 days were counted as 60 day case fatalities; these rates were then compared before and after 1 March 2020.

\section{Statistical analysis}

For each infective condition, the percentage change from the mean annual count in 2017-20 to the annual count in 2020-21 was calculated with 95\% confidence intervals, assuming a negative binomial distribution. From March 2021 onwards, these comparisons 
were undertaken on a monthly basis using the same methods. To check the consistency of findings across individual NHS hospital trusts, boxplots were plotted to show the spread of the percentage changes in each hospital trust. Sixty day all cause case fatality rates (expressed per 10000 people admitted) with 95\% exact Clopper-Pearson binomial confidence intervals were calculated for infections when the number of deaths within 60 days in every 12 month period was greater than five. Age-sex adjusted comparisons of the case fatality rates before and after 1 March 2020 were conducted using logistic regression, then further adjusted for the comorbidities listed in table 1, with further sensitivity analyses excluding people with a concurrent or previous hospital diagnosis of covid-19. Analyses were undertaken using Stata 16/MP.

\section{Data completeness}

NHS Digital are the custodians and suppliers of HES data, and we receive monthly updates but with a three month lag, meaning that a data cut received at the end of September 2021 will cover hospital admissions up to 30 June 2021. A comparison of different data cuts revealed that numbers of admissions in the most recent month of the penultimate data cut were, on average, around $84 \%$ of the numbers for the same month in the latest data cut (the numbers for May received at the end of August were about $84 \%$ of the numbers for May received at the end of September). This issue of completeness did not extend beyond the latest month of data for which numbers differed by no more than $1 \%$. To account for this incompleteness in the final month, we applied an uplift to the final month's numbers to obtain corrected numbers by applying the following calculation in relation to each infection: Obs/ (C\%), where Obs is the number of hospital admissions observed in the final month of the latest data cut and $\mathrm{C} \%$ is that month's estimated completeness based on a comparison of the latest month of the penultimate data cut and the penultimate month of the latest data cut. The same method was applied with each new data cut received. Combining all conditions, a valid value for ethnic category was present on $97.4 \%$ of records; age, sex, region, and deprivation level were complete on all records.

\section{Patient and public involvement}

Neither patients nor the public were involved in developing the research question or in the design, management, or interpretation of this study. The primary barrier was the rapid timescale of analysis to deliver timely results.

\begin{tabular}{|c|c|}
\hline Diagnosis & ICD-10 codes \\
\hline \multicolumn{2}{|l|}{ Infection category } \\
\hline \multicolumn{2}{|l|}{ Severe invasive } \\
\hline Sepsis & A40.0, A40.1, A41 \\
\hline Meningitis & A17.0, A17.8, A32.1, A85.1, A86, A87, B00.3, B00.4, B01.0, G01, G00.3, G00.8, G00.9, G02.0, G02.1, G03, G04 \\
\hline Septic arthritis & $\mathrm{M00}, \mathrm{M} 46.5$ \\
\hline Osteomyelitis & M86 \\
\hline Pyelonephritis & N10, N16.0 \\
\hline Cellulitis & L03 \\
\hline \multicolumn{2}{|l|}{ Respiratory } \\
\hline Bronchiolitis & $\mathrm{J} 21.0, \mathrm{~J} 21.1, \mathrm{~J} 21.8, \mathrm{~J} 21.9$ \\
\hline Influenza & $J 10, J 11$ \\
\hline Croup & J05, 120.9 \\
\hline Pneumonia & J12.0, J12.2, J12.8, J12.9, J13, J14, J15.0, J15.1, J15.2, J15.4, J15.5, J15.6, J15.7, J15.8, J15.9, J16.0, J17, J18, P23 \\
\hline Viral wheeze & R06.2 \\
\hline Upper respiratory tract infection & 106 \\
\hline Otitis media & $\mathrm{H} 65, \mathrm{H} 66, \mathrm{H} 67$ \\
\hline Tonsilitis & 103,136 \\
\hline \multicolumn{2}{|l|}{ Vaccine preventable } \\
\hline Neisseria meningitidis & A39 \\
\hline Haemophilus influenzae & G00.0, A41.3 \\
\hline Streptococcus pneumoniae & G00.1, A40.3 \\
\hline Measles & B05 \\
\hline Mumps & B26 \\
\hline \multicolumn{2}{|l|}{ Comorbidities } \\
\hline Asthma & 145 \\
\hline Bronchopulmonary dysplasia & P27.1 \\
\hline Extreme prematurity (<28 weeks) & P07.2 (or 'gestat' 22-27 wks) \\
\hline Cystic fibrosis & E84 \\
\hline Congenital cardiac disease & Q20, Q21, Q24 \\
\hline Bronchiectasis & 147 \\
\hline Immunodeficiency with predominantly antibody defects & D80 \\
\hline Combined immunodeficiencies & D81 \\
\hline Common variable immunodeficiency & D83 \\
\hline Acute lymphoblastic leukaemia & C91.0 \\
\hline Acute myeloid leukaemia & C92.0 \\
\hline Covid-19 & U07.1, U07.2 \\
\hline
\end{tabular}




\section{Results}

For all infections, the demographic characteristics of patients admitted in the 12 months after 1 March 2020 were similar to those observed from 1 March 2017 to 29 February 2020 except that the age distribution of admissions for pneumonia shifted more towards infants after 1 March 2020 (supplementary table 2). The proportion who had underlying comorbidities remained largely unchanged throughout the study period.

Figure 1, figure 2, and figure 3 show the number of admissions for each infection in each month from March 2017 to June 2021. In the 12 months from 1 March 2020, major reductions were found compared with the preceding 36 months in the numbers of admissions for every infection studied except pyelonephritis (fig 4). Boxplots indicated that the reductions were similar across NHS hospital trusts (supplementary fig 1).

Among the respiratory infections, the greatest percentage reduction was for influenza where the number of hospital admissions decreased by $94 \%$ (95\% confidence interval $89 \%$ to $97 \%$ ) from 5379 (annual mean from 1 March 2017 to 29 February 2020) to 304 in the 12 months after 1 March 2020. Additionally, for bronchiolitis admissions decreased by more than $80 \%$ (79\% to 84\%) from 51655 (annual mean 2017-20) to 9423 in 2020-21. For all respiratory infections, reductions were seen in all geographical regions, index of multiple deprivation classifications, and ethnic groups (supplementary fig 2). Similar reductions in admissions for respiratory conditions occurred among children with comorbidities, including asthma, bronchopulmonary dysplasia, cystic fibrosis, extremely preterm infants, and those with haematological malignancies. Compared with the mean number of admissions in the corresponding months of 2017-19, admissions for croup were 2.8 times higher than usual in May 2021 (95\% confidence interval 2.6 to 2.9) and 2.3 times higher than usual in June 2021 (1.4 to 3.8), and admissions for upper respiratory tract infections in June 2021 were 1.4 times higher than usual (1.2 to 1.6).

For five of the six severe invasive infections studied (all except pyelonephritis), substantial decreases were observed in the number of admissions. Percentage reductions ranged from 26\% (95\% confidence interval $21 \%$ to $32 \%$ ) for osteomyelitis to $50 \%$ ( $47 \%$ to $52 \%$ ) for meningitis; similar reductions were seen across all geographical regions, index of multiple deprivation classifications, and ethnic groups (supplementary fig 3).

Among the vaccine preventable infections (fig 4; supplementary fig 4), the greatest reduction was for measles where the number of admissions decreased by $90 \%$ (95\% confidence interval $80 \%$ to $95 \%$ ) from 149 (annual mean 2017-2020) to 15 in 2020-21. Admissions for Neisseria meningitidis decreased by 69\% (53\% to 80\%), while admissions for Streptococcus pneumoniae, Haemophilus influenzae, and mumps more than halved. Admissions with a diagnosis of covid-19 peaked in January 2021 (fig 4).
There were six infective conditions where the number of 60 day case fatalities exceeded five in each 12 month period: sepsis, meningitis, bronchiolitis, pneumonia, viral wheeze, and upper respiratory tract infections. Alongside the decrease in admissions for these conditions, there was a decrease in the absolute number of 60 day fatalities. For pneumonia, although the absolute number of 60 day fatalities decreased (from a three year average of 193 in 2017-20 to 156 after 1 March 2020), the proportion admitted who died within 60 days increased after the onset of the pandemic (age-sex adjusted odds ratio 1.73, 95\% confidence interval 1.42 to 2.11). Further adjusting for comorbidities attenuated the odds ratio $(1.62,1.35$ to 1.94); additionally removing 455 patients who had a hospital recorded diagnosis of covid-19 (representing $7 \%$ of the total admissions with pneumonia in 202021) did not alter the effect size further $(1.61,1.34$ to 1.94; table 2).

\section{Discussion}

\section{Principal findings}

Since the onset of the covid-19 pandemic, there have been major reductions in hospital admissions for respiratory, severe invasive, and vaccine preventable infections in children in England. These reductions were seen in all demographic subgroups, including in children with pre-existing comorbidities who are more likely to be admitted to hospital with severe disease, require prolonged intensive care support, and be at greatest risk from dying of infection.

The findings indicate the extent to which measures related to the control of covid-19 can also impact on the transmission of other specific infectious diseases in childhood. Before the pandemic, bronchiolitis accounted for $12 \%$ of all admissions to paediatric intensive care units and had a case fatality rate of $1.75 \%$ in children aged $<12$ months and $4.4 \%$ in children aged $\geq 12$ months. ${ }^{22}$ Exacerbation of asthma caused by acute respiratory infections was also one of the commonest reasons for hospital admission in children. In this study, after 1 March 2020, we report substantial reductions in admissions for bronchiolitis (80\%), viral wheeze (56\%), and predominantly bacterial causes of childhood respiratory infection: $60 \%$ reduction in the overall number of children admitted with pneumonia, $74 \%$ reduction for otitis media, and $66 \%$ reduction for tonsillitis. Children with haematological malignancies and cystic fibrosis who are most susceptible to major bacterial infections also had lower incidence of admission for respiratory infections compared with previous years (supplementary fig 2). Children with respiratory infections account for high healthcare costs, substantial morbidity, and in rare instances, mortality.

\section{Contributing causes and implications for the future} While the pattern of hospital recorded covid-19 is probably almost entirely driven by universal testing for the infection at the point of admission for any medical or surgical condition, the dramatic reduction in transmission rates of non-covid-19 infectious 

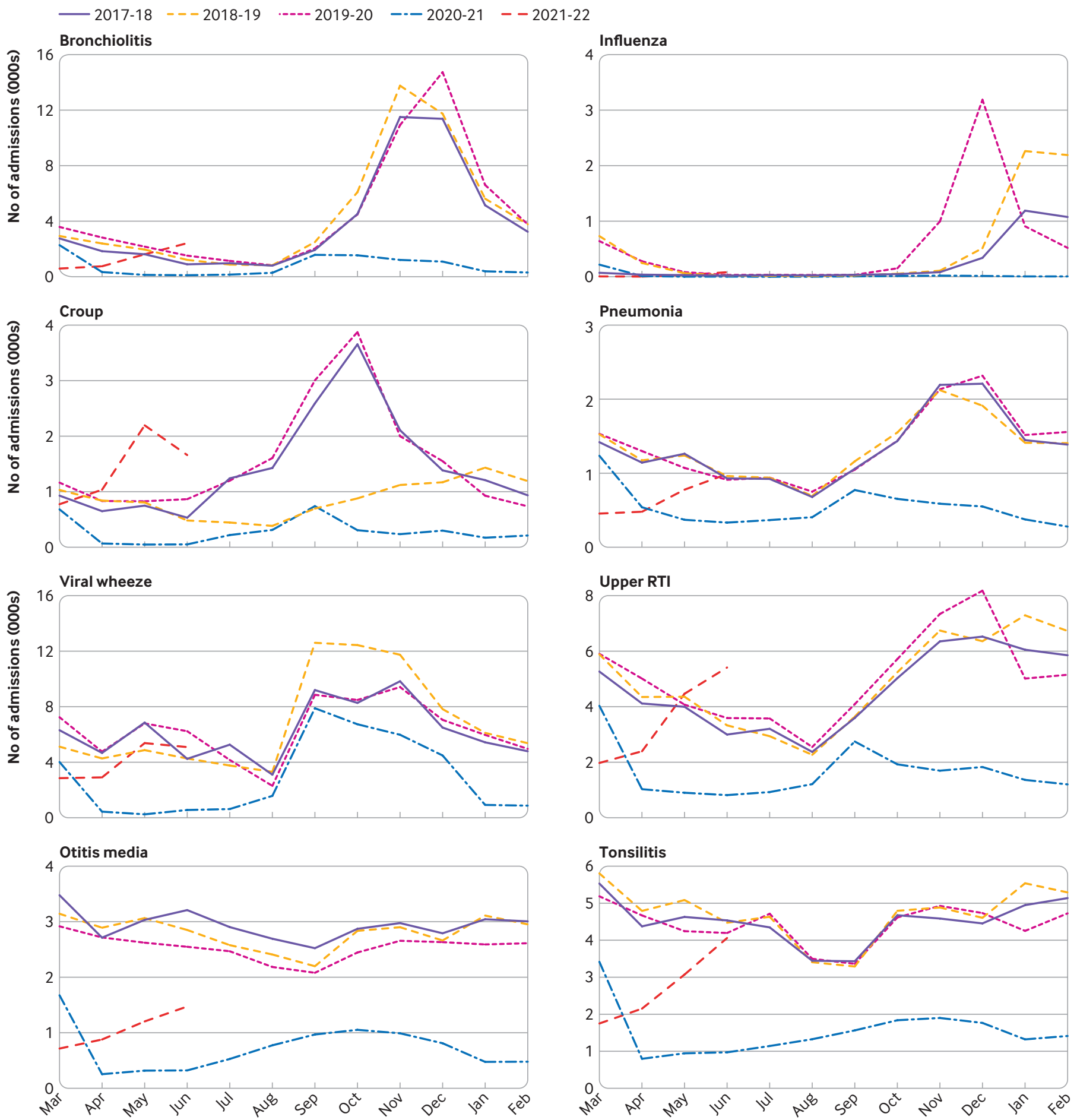

Fig 1 | Monthly admissions for respiratory infections in England from March 2017 to June 2021. RTI=respiratory tract infection

pathogens among children is probably because of changes in patterns of social contact (social distancing, school closures, and minimal recreational activities) and shielding measures (at risk groups). Vastly restricted domestic and international travel (reduced air pollution) might have also contributed to the reduction in childhood respiratory infections. ${ }^{1623}$ However, these measures are generally unsustainable outside of the pandemic because of their inherent negative financial and societal impact.
The immediate and substantial reduction in respiratory and severe invasive childhood infections is also probably caused by the widespread introduction of non-pharmacological interventions. A range of behavioural measures, including face masks, better and regular hand hygiene, improved respiratory etiquette, and environmental cleaning have been adopted across homes, schools, and workplaces in England, which helped in reducing transmission of SARS-CoV-2. ${ }^{24}$ Our data indicate that these interventions might have also 

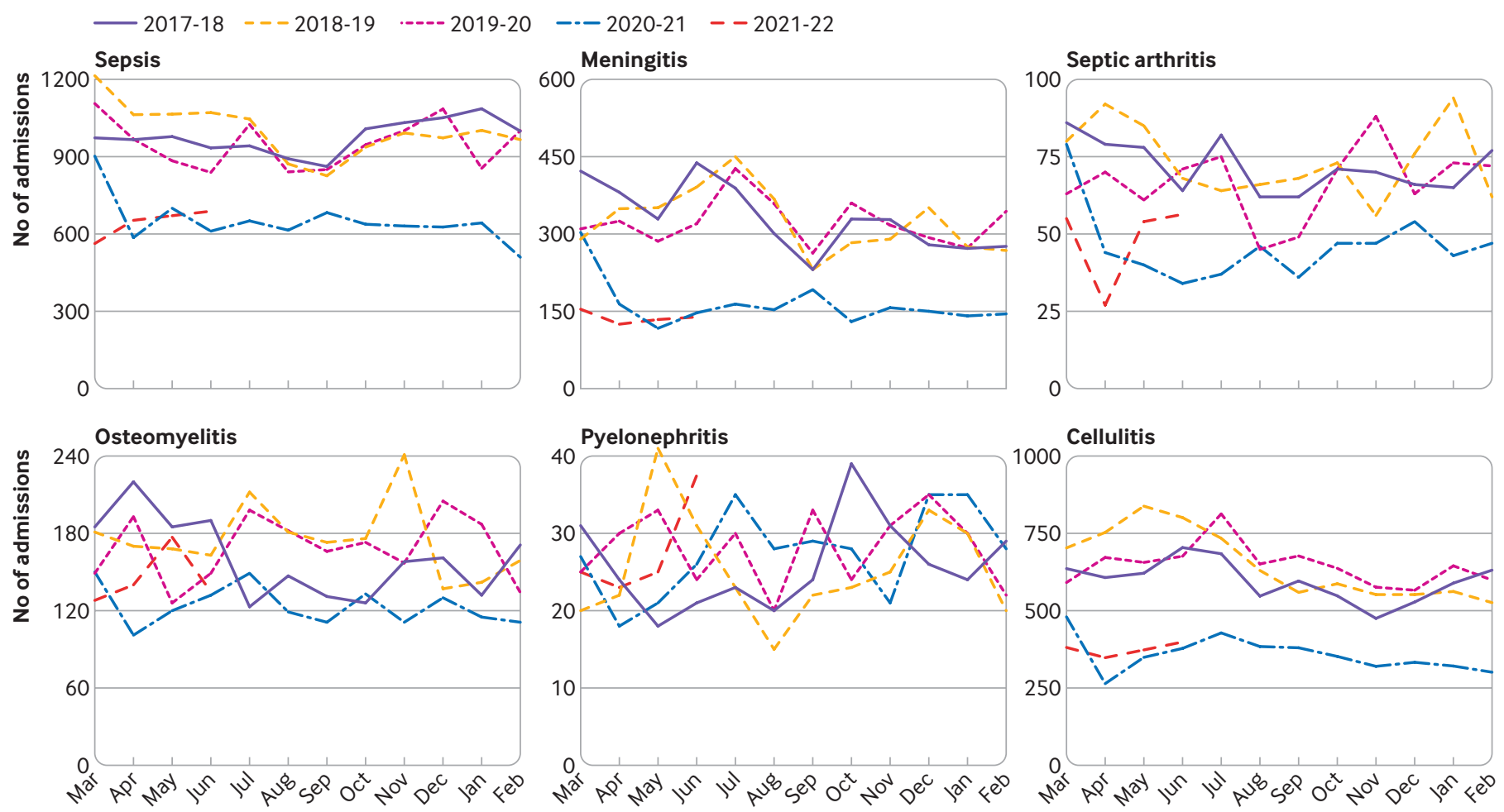

Fig 2 | Monthly admissions for severe invasive infections in England from March 2017 to June 2021

minimised childhood transmission of non-covid-19 infections. In particular, this study has highlighted that children with severe underlying comorbidities, including extremely preterm infants, those with congenital cardiac disease, and those with asthma have been protected from severe and potentially life threatening infection.
School closures might have contributed to some of the reductions seen in this study, but it was not possible to disentangle the effects of school closures and other policies around physical distancing. School closures during influenza pandemics have been shown to reduce epidemic peaks, but conflicting evidence exists about
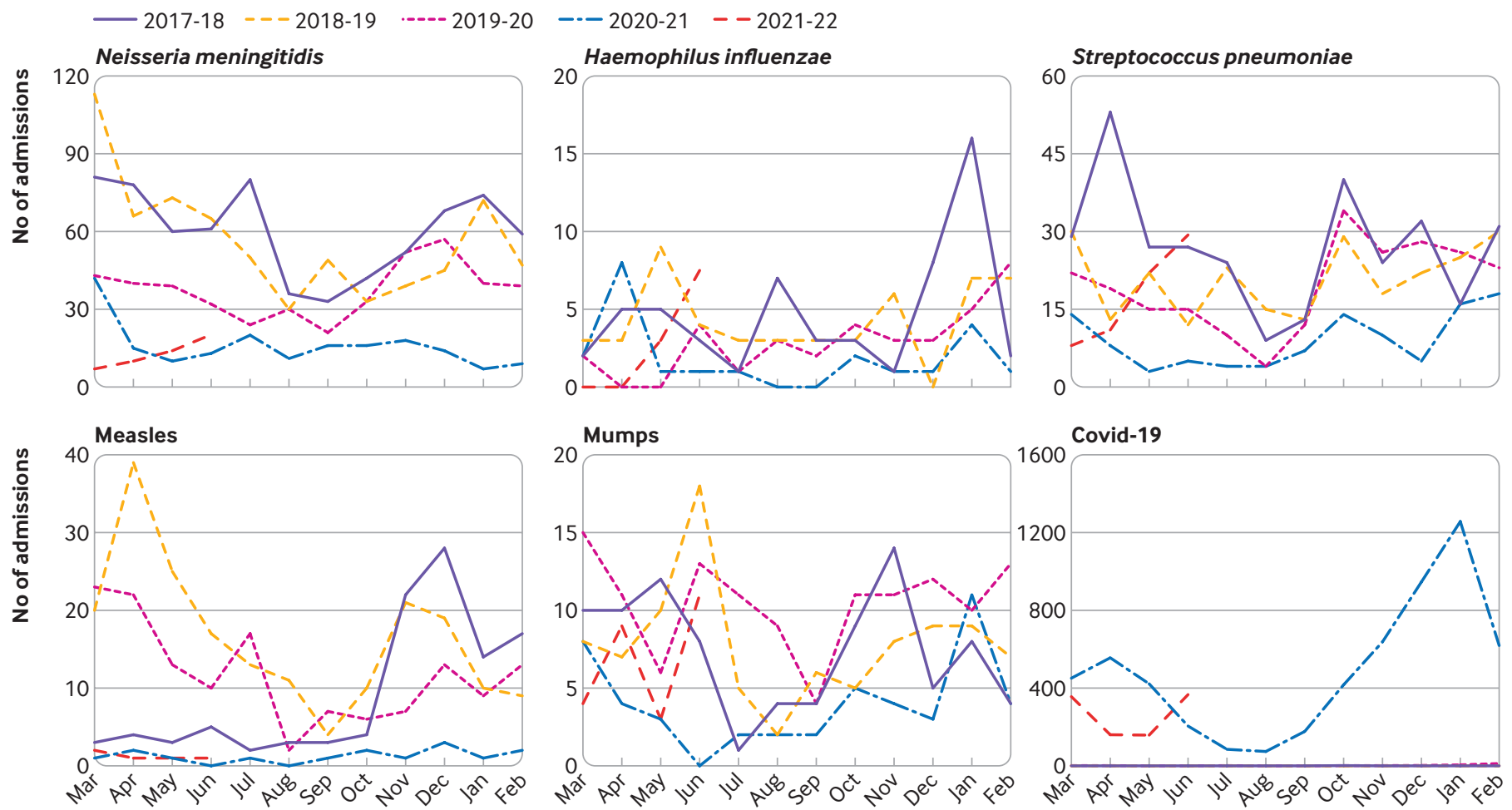

Fig 3 | Monthly admissions for vaccine preventable infections in England from March 2017 to June 2021 


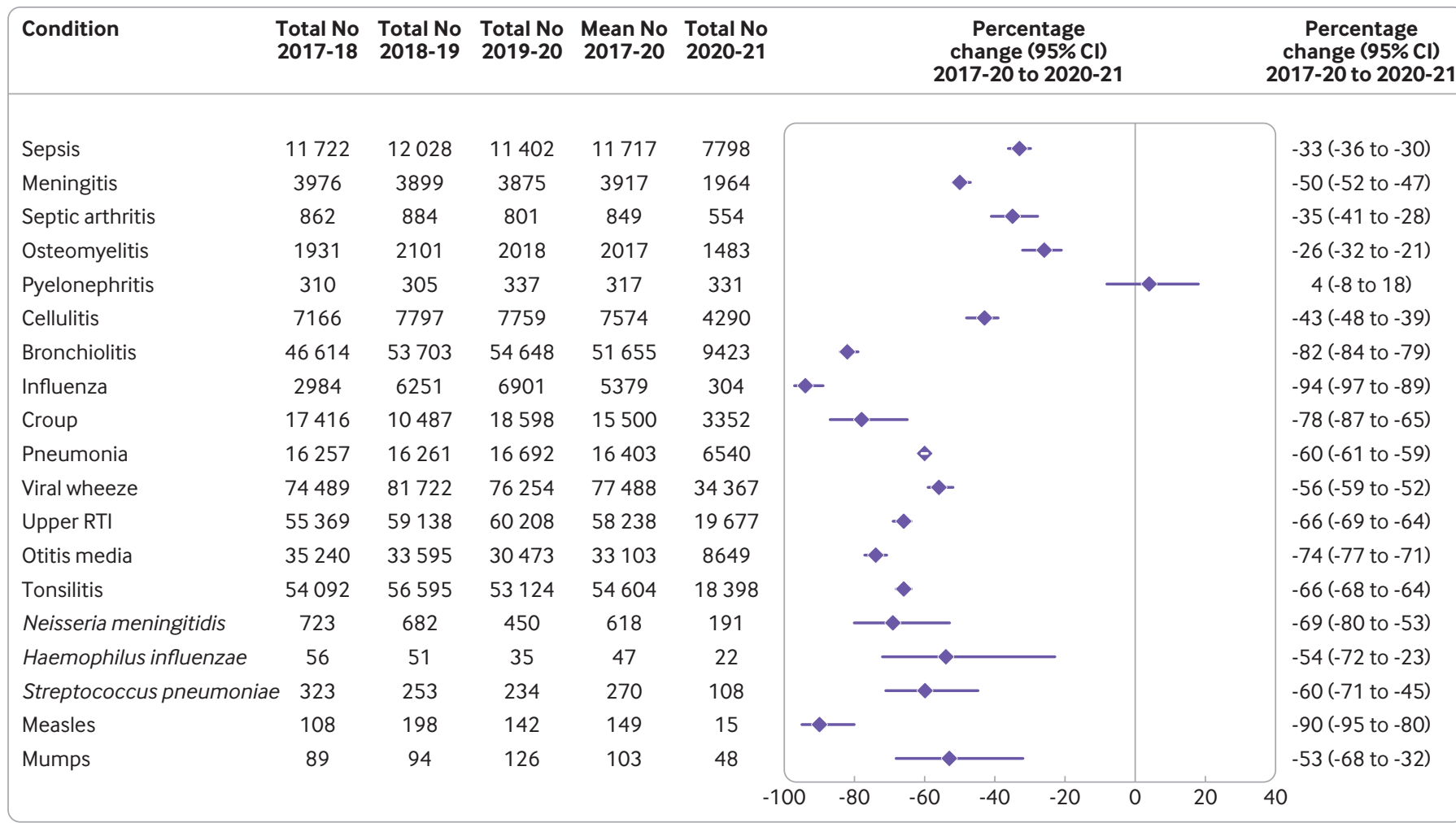

Fig 4 | Number of hospital admissions in each 12 month period (March-February), and percentage change from March 2017-February 2020 (mean over three years) to March 2020-February 2021. RTI=respiratory tract infection

optimal timing and duration. The success of school closures is largely dependent on the characteristics of the circulating influenza serotype and when transmission is higher in children than adults. ${ }^{24} 25$ National surveillance data in 11966 children from 131 schools in England showed extremely low rates of SARS-CoV-2 infection and transmission in children aged up to 11 years at the point of school closure and also at reopening. ${ }^{26}$ During the covid-19 pandemic, good hygiene practices have been implemented (hand sanitisers in classrooms, regular hand washing, education on respiratory etiquette) along with measures to minimise spread of infection (avoiding overcrowding and good ventilation in classrooms). Furthermore, children with respiratory symptoms were excluded until confirmed to have a negative covid-19 test. Ensuring children with symptoms are off school, and encouraging employers to support parents to be at home with their

\begin{tabular}{|c|c|c|c|c|c|c|c|c|c|}
\hline \multirow[b]{2}{*}{ Condition } & \multirow[b]{2}{*}{$\begin{array}{l}60 \text { day case } \\
\text { fatalities }\end{array}$} & \multirow[b]{2}{*}{$\begin{array}{l}\text { March } 2017 \text { to } \\
\text { February } 2018\end{array}$} & \multirow[b]{2}{*}{$\begin{array}{l}\text { March } 2018 \text { to } \\
\text { February } 2019\end{array}$} & \multirow[b]{2}{*}{$\begin{array}{l}\text { March } 2019 \text { to } \\
\text { February } 2020\end{array}$} & \multirow[b]{2}{*}{$\begin{array}{l}\text { March } 2020 \text { to } \\
\text { February } 2021\end{array}$} & \multicolumn{2}{|l|}{ Model 1* } & \multicolumn{2}{|l|}{ Model 2* } \\
\hline & & & & & & $\begin{array}{l}\text { Adjusted odds } \\
\text { ratio }(95 \% \mathrm{Cl})\end{array}$ & $P$ value & $\begin{array}{l}\text { Adjusted odds } \\
\text { ratio }(95 \% \mathrm{Cl})\end{array}$ & $P$ value \\
\hline \multirow[b]{2}{*}{ Sepsis } & No of deaths/cases & $148 / 11722$ & $163 / 12028$ & $158 / 11402$ & $110 / 7798$ & \multirow[b]{2}{*}{1.03 (0.84 to 1.27$)$} & \multirow[b]{2}{*}{0.77} & \multirow[b]{2}{*}{$1.00(0.81$ to 1.24$)$} & \multirow[b]{2}{*}{0.98} \\
\hline & $\begin{array}{l}\text { Rate per } 10000 \\
\text { cases }(95 \% \mathrm{Cl})\end{array}$ & 126 (107 to 148$)$ & 136 (116 to 158$)$ & 139 (118 to 162$)$ & 141 (116 to 170$)$ & & & & \\
\hline \multirow[b]{2}{*}{ Meningitis } & No of deaths/cases & $29 / 3976$ & $38 / 3899$ & $31 / 3875$ & $21 / 1964$ & \multirow[b]{2}{*}{1.28 (0.79 to 2.05$)$} & \multirow[b]{2}{*}{0.31} & \multirow[b]{2}{*}{1.07 (0.66 to 1.73$)$} & \multirow[b]{2}{*}{0.78} \\
\hline & $\begin{array}{l}\text { Rate per } 10000 \\
\text { cases }(95 \% \mathrm{Cl})\end{array}$ & 73 (49 to 105$)$ & 97 (69 to 134) & 80 (54 to 113$)$ & 107 (66 to 163) & & & & \\
\hline \multirow[b]{2}{*}{ Bronchiolitis } & No of deaths/cases & $69 / 46614$ & $55 / 53703$ & $65 / 54648$ & $16 / 9423$ & \multirow[b]{2}{*}{1.35 (0.81 to 2.26$)$} & \multirow[b]{2}{*}{0.25} & \multirow[b]{2}{*}{1.18 (0.71 to 1.98$)$} & \multirow[b]{2}{*}{0.52} \\
\hline & $\begin{array}{l}\text { Rate per } 10000 \\
\text { cases }(95 \% \mathrm{Cl})\end{array}$ & 15 (12 to 19$)$ & 10 (8 to 13$)$ & 12 (9 to 15$)$ & 17 (10 to 28$)$ & & & & \\
\hline \multirow[b]{2}{*}{ Pneumonia } & No of deaths/cases & $196 / 16257$ & $212 / 16261$ & $172 / 16692$ & $156 / 6540$ & \multirow[b]{2}{*}{1.71 (1.43 to 2.05$)$} & \multirow[b]{2}{*}{$P<0.001$} & \multirow[b]{2}{*}{$1.62(1.35$ to 1.94$)$} & \multirow[b]{2}{*}{$P<0.001$} \\
\hline & $\begin{array}{l}\text { Rate per } 10000 \\
\text { cases }(95 \% \mathrm{Cl})\end{array}$ & 121 (104 to 139$)$ & 130 (114 to 149) & 103 (88 to 120 ) & 239 (203 to 278) & & & & \\
\hline \multirow[b]{2}{*}{ Viral wheeze } & No of deaths/cases & $17 / 74489$ & $14 / 81722$ & $14 / 76254$ & $9 / 34367$ & \multirow[b]{2}{*}{1.47 (0.71 to 3.01$)$} & \multirow[b]{2}{*}{0.30} & \multirow[b]{2}{*}{1.51 (0.73 to 3.1$)$} & \multirow[b]{2}{*}{0.26} \\
\hline & $\begin{array}{l}\text { Rate per } 10000 \\
\text { cases }(95 \% \mathrm{Cl})\end{array}$ & 2 (1 to 4$)$ & 2 (1 to 3$)$ & 2 (1 to 3$)$ & $3(1$ to 5$)$ & & & & \\
\hline \multirow[b]{2}{*}{ Upper RTI } & No of deaths/cases & $40 / 55369$ & $42 / 59138$ & $26 / 60208$ & $15 / 19677$ & \multirow[b]{2}{*}{1.22 (0.71 to 2.09$)$} & \multirow[b]{2}{*}{0.48} & \multirow[b]{2}{*}{1.19 (0.69 to 2.04) } & \\
\hline & $\begin{array}{l}\text { Rate per } 10000 \\
\text { cases }(95 \% \mathrm{Cl})\end{array}$ & 7 (5 to 10$)$ & 7 (5 to 10$)$ & 4 (3 to 6) & 8 (4 to 13$)$ & & & & 0.53 \\
\hline
\end{tabular}

RTI=respiratory tract infection.

*Model 1: adjusted for age and sex; model 2: adjusted for age, sex, and comorbidities in table 1. All odds ratios compare 60 day case fatality from March 2020 to February 2021 with reference period from March 2017 to February 2020. 
unwell child, could help reduce the burden of childhood infections transmitted at school. However, a systematic review that included 72 observational studies assessed the impact of school closures on the mental health of children during covid-19 and showed increased anxiety, depressive and emotional behaviours. ${ }^{27}$ Preliminary observational data from France suggest there had been no increase in the rates of common respiratory infections among children immediately after the reopening of schools after national lockdown measures were lifted ${ }^{15}$; this could be because of societal behaviours persisting immediately after schools reopened and unwell children being kept home. Further analysis is required to assess which measures might be maintained in future to reduce transmission of infections more broadly while avoiding the negative impact of closing schools. Ongoing clinical and microbiological surveillance is required to evaluate any epidemiological changes (eg, substantial increase in rates, delayed peaks, disease in older infants) in respiratory infections that might have occurred because of a lack of population based immunity during the pandemic. The unusually high rates of croup and upper respiratory tract infections in the last months of this study (in May and June 2021) further underline this need.

The reduction in musculoskeletal infections could be because of decreased exposure to Staphylococcus aureus and Kingella kingae, which are the commonest causative pathogens. The larger reductions seen in hospital admission due to cellulitis, compared with septic arthritis or osteomyelitis, might be because these children were treated with oral antibiotics and could be more easily managed at home compared with those with bone and joint infection. The epidemiology of bone and joint infections in children is poorly understood because of a lack of clinical or microbiological surveillance. These data could encourage future studies to evaluate the cause (eg, contribution of preceding respiratory infections, trauma, or underlying comorbidities) to better inform management strategies.

Our data also show important reductions in respiratory infections among children with preexisting lung disease. To obtain a holistic overview of protective mechanisms that have reduced hospital admissions for respiratory infections in these patients, there is a need for more quantitative data (changes in patterns to elective admissions, exposure to respiratory pathogens, colonisation with resistant pathogens) and qualitative data (from children and their caregivers).

The absence of any reduction in admissions for pyelonephritis might be because non-pharmacological interventions and social restrictions have no impact on this condition; the slight percentage increase $(4 \%$, $95 \%$ confidence interval $-8 \%$ to $18 \%$ ), though not statistically significant, could be caused by delays in presentation for children who had uncomplicated urinary tract infections that might have progressed to ascending infection by the time of hospital attendance.

Reductions in bacterial pathogens during the covid-19 pandemic, which have been reported in laboratory confirmed data from 26 countries worldwide, ${ }^{28}$ might be caused by fewer social interactions limiting the transmission of vaccine preventable infections. ${ }^{2930}$ However, these reductions might also be partly caused by reduced circulating respiratory viral infections (in particular, respiratory syncytial virus and influenza), which can increase susceptibility to pneumococcal and meningococcal disease. In regions with interrupted vaccination programmes, active enhanced surveillance mechanisms and catch up vaccination programmes should be prioritised to identify any resurgence in vaccine preventable infections and ensure herd immunity is maintained.

Reduced hospital attendance could be partly due to reluctance to attend the emergency department during a pandemic and potentially being exposed to SARS-CoV-2. Reassuringly, this study indicates that the pandemic has not had an adverse effect on absolute numbers of fatalities because deaths within 60 days have also reduced alongside hospital admissions (investigation of death rates from infections among children who did not have a related hospital admission was outside the scope of this study). However, for pneumonia, although the absolute number of 60 day fatalities decreased, the proportion admitted who died within 60 days increased. This increase could be because hospital admissions for pneumonia after 1 March 2020 were generally at the more severe end of the spectrum if people with less severe disease were being more frequently managed outside hospital or because of delays in seeking or difficulty in accessing appropriate healthcare during the pandemic. At the Royal Children's Hospital in Melbourne, the Hospital in The Home service observed that a dedicated outpatient team can safely manage children with meningitis, severe cellulitis, and complex urinary tract infections in their home. ${ }^{31-33}$ This service has been shown to deliver cost savings to the healthcare provider and improves quality of life for the child and caregiver. Future work should include caregiver perceptions in seeking healthcare during the pandemic to minimise anxiety, ensure clear public health messaging that encourages caregivers to attend emergency departments when necessary, and develop outpatient services to manage children with infection in the community if appropriate.

\section{Strengths and limitations}

The strengths of this study include the national coverage of data available because they capture all relevant hospital admissions for the entire child population of England over several years; determination of underlying comorbidities based on patients' entire previous NHS hospital admission history; and the inclusion of a range of different infections providing the means to compare them. This study has some limitations. The reliability of HES data is dependent on information collected from clinical notes and clinical coding practice, which is important when comparing data from one year to the next because the quality might vary. Beyond the clinical diagnoses (ICD-10 codes), no other clinical or 
microbiological data were available. Therefore, disease severity (such as admission to paediatric intensive care unit) could not be evaluated and ICD codes could not be corroborated with laboratory results. The HES data represent hospital admissions for infection and do not necessarily provide a complete picture of the true rates of actual infection in the population as they do not cover patients who did not attend an NHS hospital (eg, owing to patient or caregiver reluctance or possible shortage of healthcare provision) or those who only attended the emergency department or outpatient settings (that is, they did not require inpatient admission). For comorbidity data, although we were able to look back historically at each patient's entire NHS hospital admission history, comorbidity profiles might be incomplete because the data did not cover emergency department or outpatient settings (only inpatient admissions and day cases), primary care, or non-NHS care.

\section{Comparison with other studies}

This large epidemiological study evaluates the impact of covid-19 on hospital admission rates for childhood infections. Similar findings have been reported in regional studies in Australia, Denmark, France, and the Netherlands, with reported reductions of more than $50 \%$ in paediatric attendances with common infectious diseases. ${ }^{34-36}$ However, it would be valuable to establish similar continuous analyses in other locations where centralised electronic health record data are available (eg, China, Taiwan, or Sweden, or in health maintenance organisations in the United States) to monitor such trends until the challenges associated with the pandemic diminish.

\section{Conclusions}

This study has shown dramatic overall reductions in hospital admissions for respiratory, severe invasive, and vaccine preventable infections in children during the covid-19 pandemic in England. Children with potentially life threatening comorbidities were also substantially protected. Further evaluation of nonpharmacological interventions that could be sustained beyond the pandemic is required to inform policy makers about potential strategies, especially during winter months, to minimise the burden on health systems and protect vulnerable children. Continued monitoring of hospital admissions for these infections is required as social restrictions evolve.

Contributors: SK and RG contributed equally as joint first authors. All authors conceived the study question. SK and RG wrote the first draft of the manuscript. SK conducted the literature review. RG conducted the analyses. All authors contributed to subsequent drafts and interpretation of the findings. SK and RG are study guarantors. The corresponding author attests that all listed authors meet authorship criteria and that no others meeting the criteria have been omitted.

Funding: Office for Health Improvement and Disparities, Health Data Research UK, and the National Institute for Health Research Oxford Biomedical Research Centre. The funders had no role in study design, data collection, data analysis, data interpretation, or writing of the report.

Competing interests: All authors have completed the ICMJE uniform disclosure form at www.icmje.org/disclosure-of-interest/ and declare: support from Office for Health Improvement and Disparities, Health
Data Research UK, and the National Institute for Health Research Oxford Biomedical Research Centre for the submitted work; grants from the National Institute for Health Research, Bill and Melinda Gates Foundation, Wellcome Trust, and Astra Zeneca in the previous three years; no other relationships or activities that could appear to have influenced the submitted work.

Ethical approval: All patient records were pseudonymised by the data providers through encryption of personal identifiers. Ethical approval to hold and analyse the record-linked datasets in the Unit of Health-Care Epidemiology was obtained from the Central and South Bristol Multi-Centre Research Ethics Committee (04/Q2006/176).

Data sharing: The dataset used in this study can be obtained by successful application to NHS Digital.

The lead authors (the manuscript's guarantors) affirm that the manuscript is an honest, accurate, and transparent account of the study being reported; that no important aspects of the study have been omitted; and that any discrepancies from the study as planned (and, if relevant, registered) have been explained.

Dissemination to participants and related patient and public communities: The project team will continue to update the analyses based on these data sources and publish them (alongside any developments to the methods used) at https://www.ctsu.ox.ac.uk/ research/indirect-effects-of-the-covid-19-pandemic-on-childhoodinfection-in-england. This study will also be disseminated by our institutions' social media channels.

Provenance and peer review: Not commissioned; externally peer reviewed.

This is an Open Access article distributed in accordance with the terms of the Creative Commons Attribution (CC BY 4.0) license, which permits others to distribute, remix, adapt and build upon this work, for commercial use, provided the original work is properly cited. See: http://creativecommons.org/licenses/by/4.0/.

1 Stokes EK, Zambrano LD, Anderson KN, et al. Coronavirus disease 2019 case surveillance - United States, January 22-May 30, 2020 MMWR Morb Mortal Wkly Rep 2020;69:759-65. doi:10.15585/ mmwr.mm6924e2

2 Wu Z, McGoogan IM. Characteristics of and important lessons from the coronavirus disease 2019 (covid-19) outbreak in China: summary of a report of 72314 cases from the Chinese Center for Disease Control and Prevention. JAMA 2020;323:1239-42. doi:10.1001/jama.2020.2648

3 Swann OV, Holden KA, Turtle L, et al, ISARIC4C Investigators. Clinical characteristics of children and young people admitted to hospital with covid-19 in United Kingdom: prospective multicentre observational cohort study. BMJ 2020;370:m3249. doi:10.1136/bmj.m3249

4 Dong Y, Mo X, Hu Y, et al. Epidemiological characteristics of 2143 pediatric patients with 2019 coronavirus disease in China. J Emerg Med 2020;58:712-3. doi:10.1016/j.jemermed.2020.04.006

5 Götzinger F, Santiago-García B, Noguera-Julián A, et al, ptbnet COVID-19 Study Group. COVID-19 in children and adolescents in Europe: a multinational, multicentre cohort study. Lancet Child Adolesc Health 2020;4:653-61. doi:10.1016/S2352-4642(20)30177-2

6 American Acadamy of Pediatrics. Children and COVID-19: state-level data report. Critical updates on COVID-19. 2021. https://services. aap.org/en/pages/2019-novel-coronavirus-covid-19-infections/ children-and-covid-19-state-level-data-report/

7 Lynn RM, Avis IL, Lenton S, Amin-Chowdhury Z, Ladhani SN. Delayed access to care and late presentations in children during the COVID-19 pandemic: a snapshot survey of 4075 paediatricians in the UK and Ireland. Arch Dis Child 2021;106:e8. doi:10.1136/ archdischild-2020-319848

8 Lazzerini M, Barbi E, Apicella A, Marchetti F, Cardinale F, Trobia G. Delayed access or provision of care in Italy resulting from fear of COVID-19. Lancet Child Adolesc Health 2020;4:e10-1. doi:10.1016 S2352-4642(20)30108-5

9 Kadambari S, Abo YN, Phuong LK, Osowicki J, Bryant PA. Decrease in infection-related hospital admissions during COVID-19: Why are parents avoiding the doctor?Pediatr Infect Dis / 2020;39:e385-6. doi:10.1097/INF.0000000000002870

10 World Health Organization. At least 80 million children under one at risk of diseases such as diphtheria, measles and polio as COVID-19 disrupts routine vaccination efforts, warn Gavi, WHO and UNICEF. 2020. https://www.who.int/news-room/detail/22-05-2020-atleast-80-million-children-under-one-at-risk-of-diseases-suchas-diphtheria-measles-and-polio-as-covid-19-disrupts-routinevaccination-efforts-warn-gavi-who-and-unicef

11 WHO Regional Office for Europe. Ministers back 5-year plan to put health in Europe on track. 2020. https://www.euro.who.int/en/ media-centre/sections/press-releases/2020/ministers-back-5-yearplan-to-put-health-in-europe-on-track 
12 McDonald HI, Tessier E, White JM, et al. Early impact of the coronavirus disease (COVID-19) pandemic and physical distancing measures on routine childhood vaccinations in England, January to April 2020. Euro Surveill 2020;25:2000848. doi:10.2807/15607917.ES.2020.25.19.2000848

13 NHS Digital. Childhood vaccination coverage statistics, England 2019-20. Childhood vaccination coverage statistics. 2020. https:// digital.nhs.uk/data-and-information/publications/statistical/nhsimmunisation-statistics/england-2019-20

14 Isba R, Edge R, Jenner R, Broughton E, Francis N, Butler J. Where have all the children gone? Decreases in paediatric emergency department attendances at the start of the COVID-19 pandemic of 2020. Arch Dis Child 2020;105:704. doi:10.1136/archdischild-2020-319385

15 Angoulvant F, Ouldali N, Yang DD, et al. Coronavirus disease 2019 pandemic: impact caused by school closure and national lockdown on pediatric visits and admissions for viral and nonviral infections-a time series analysis. Clin Infect Dis 2021;72:319-22. doi:10.1093/ cid/ciaa710

16 Williams TC, MacRae C, Swann OV et al. Indirect effects of the COVID-19 pandemic on paediatric healthcare use and severe disease: a retrospective national cohort study. Arch Dis Child 2021;106:911-7. doi:10.1136/archdischild-2020-321008

17 Yeoh DK, Foley DA, Minney-Smith CA, et al. Impact of coronavirus disease 2019 public health measures on detections of influenza and respiratory syncytial virus in children during the 2020 Australian winter. Clin Infect Dis 2021:72:2199-202. doi:10.1093/cid/ ciaa1475

18 Vásquez-Hoyos P, Diaz-Rubio F, Monteverde-Fernandez N, et al, LARed Network. Reduced PICU respiratory admissions during COVID-19. Arch Dis Child 2020. doi:10.1136/ archdischild-2020-320469

19 Fricke LM, Glöckner S, Dreier M, Lange B. Impact of nonpharmaceutical interventions targeted at COVID-19 pandemic on influenza burden - a systematic review. J Infect 2021;82:1-35 doi:10.1016/j.jinf.2020.11.039

20 Brown J, Kirk-Wade E. Coronavirus: a history of English lockdown laws. House of Commons Library: Briefing paper number 9068 2021. https://researchbriefings.files.parliament.uk/documents/CBP9068/CBP-9068.pdf

21 Ministry of Housing, Communities and Local Government. The English Indices of Deprivation. 2019. https://assets.publishing.service. gov.uk/government/uploads/system/uploads/attachment data/ file/853811/loD2019 FAQ v4 pdf

22 Green CA, Yeates D, Goldacre A, et al. Admission to hospital for bronchiolitis in England: trends over five decades, geographical variation and association with perinatal characteristics and subsequent asthma. Arch Dis Child 2016;101:140-6. doi:10.1136/ archdischild-2015-308723

23 Krivec U, Kofol Seliger A, Tursic J. COVID-19 lockdown dropped the rate of paediatric asthma admissions. Arch Dis Child 2020;105:80910. doi:10.1136/archdischild-2020-319522

24 Flaxman S, Mishra S, Gandy A, et al, Imperial College COVID-19 Response Team. Estimating the effects of non-pharmaceutical interventions on COVID-19 in Europe. Nature 2020;584:257-61. doi:10.1038/s41586-020-2405-7
25 Jackson C, Mangtani P, Hawker J, Olowokure B, Vynnycky E. The effects of school closures on influenza outbreaks and pandemics: systematic review of simulation studies. PLoS One 2014:9:e97297. doi:10.1371/journal.pone.0097297

26 Ladhani SN, Baawuah F, Beckmann J, et al. SARS-CoV-2 infection and transmission in primary schools in England in June-December, 2020 (sKIDs): an active, prospective surveillance study. Lancet Child Adolesc Health 2021;5:417-27. doi:10.1016/S23524642(21)00061-4

27 Viner R, Russell S, Saulle R, et al. Impacts of school closures on physical and mental health of children and young people: a systematic review.medRxiv 2021. doi:10.1101/2021.02.10.21251526

28 Brueggemann AB, Jansen van Rensburg MJ, Shaw D, et al. Changes in the incidence of invasive disease due to Streptococcus pneumoniae, Haemophilus influenzae, and Neisseria meningitidis during the COVID-19 pandemic in 26 countries and territories in the Invasive Respiratory Infection Surveillance Initiative: a prospective analysis of surveillance data. Lancet Digit Health 2021;3:e360-70. doi:10.1016/S2589-7500(21)00077-7

29 Brunstein JD, Cline CL, McKinney S, Thomas E. Evidence from multiplex molecular assays for complex multipathogen interactions in acute respiratory infections. J Clin Microbiol 2008;46:97-102. doi:10.1128/JCM.01117-07

30 Moore DP, Dagan R, Madhi SA. Respiratory viral and pneumococca coinfection of the respiratory tract: implications of pneumococcal vaccination. Expert Rev Respir Med 2012;6:451-65. doi:10.1586 ers.12.32

31 Scanlan BT, Ibrahim LF, Hopper SM, Babl FE, Davidson A, Bryant PA. Selected children with complicated acute urinary tract infection may be treated with outpatient parenteral antibiotic therapy at home directly from the emergency department. Pediatr Infect Dis / 2019;38:e20-5. doi:10.1097/INF.0000000000002070

32 Hensey CC, Sett A, Connell TG, Bryant PA. A comparison of hospital versus outpatient parenteral antibiotic therapy at home for pyelonephritis and meningitis. Pediatr Infect Dis / 2017;36:827-32. doi:10.1097/INF.0000000000001605

33 Ibrahim LF, Hopper SM, Babl FE, Bryant PA. Who can have parentera antibiotics at home?: A prospective observational study in children with moderate/severe cellulitis. Pediatr Infect Dis / 2016;35:269-74. doi:10.1097/INF.0000000000000992

34 Todd IMF, Miller JE, Rowe SL, Burgner DP, Sullivan SG. Changes in infection-related hospitalizations in children following pandemic restrictions: an interrupted time-series analysis of total population data. Int J Epidemiol 2021;50:1435-43. doi:10.1093/ije/dyab101

35 Polcwiartek LB, Polcwiartek C, Andersen MP, et al. Consequences of coronavirus disease-2019 (COVID-19) lockdown on infection-related hospitalizations among the pediatric population in Denmark. Eur J Pediatr 2021;180:1955-63. doi:10.1007/s00431-021-03934-2

36 Kruizinga MD, Peeters D, van Veen M et al. The impact of lockdown on pediatric ED visits and hospital admissions during the COVID19 pandemic: a multicenter analysis and review of the literature. Eur J Pediatr 2021;180:2271-9. doi:10.1007/s00431-021-04015-0

Web appendix: Supplementary materials 